Philosophical Perspectives, 33, 2019

doi: $10.1111 /$ phpe. 12128

\title{
ASYMMETRIES IN THE VALUE OF EXISTENCE
}

\author{
Jacob M. Nebel
}

\section{Introduction}

Can it be better for a person to exist than not to exist? The philosophical literature contains two main answers to this very old question. ${ }^{1}$

Symmetric comparativists say Yes: that it is better for a person to have a good life - a life worth living - than not to exist, and worse for a person to have a bad life - a life worth not living - than not to exist. ${ }^{2}$ Noncomparativists say No: that it cannot be better or worse, in any respect, for a person to exist than not to exist. ${ }^{3}$

There are reasons to be dissatisfied with both answers.

First consider symmetric comparativism. Suppose that you can create a person with a good life, in a way that would affect no one else. According to symmetric comparativism, this act would be better for that person than not creating her. Intuitively, if an act would make things better for the only person affected by it, then we have some moral reason to perform that act. But, many people believe, you have no moral reason to create a person with a life worth living, in a way that would affect no one else. Intuitively, the creation of lives worth living is morally neutral. ${ }^{4}$ That is hard to square with symmetric comparativism. ${ }^{5}$

Next consider noncomparativism. Consider a person whose life is filled only with unmitigated suffering. It seems to me that we would have most reason to prefer, for the sake of this person, that she had never lived. Creating such a person would not only be wrong; it would wrong her. Intuitively, it would wrong her because it would harm her. According to noncomparativism, though, this act could not be worse for her, in any respect, than not creating her. But, plausibly, if anyone would have most reason to prefer, for someone's sake, that $p$, then it would have been better for that person if $p$. And, we might think, an act can wrong a person by virtue of harming her only if it's of a kind that, under normal conditions, has some risk of making the person worse off at some time, in some respect, than some alternative. ${ }^{6}$ That is hard to square with noncomparativism.

These judgments and principles are controversial. But I take their prima facie plausibility to be reason enough to explore other possible views about the value of existence. In this paper, I speculatively explore an alternative view, which I call asymmetric comparativism. 
According to asymmetric comparativism, it is worse for a person to have a bad life than not to exist. But it isn't better for a person to have a good life than not to exist. (Nor is there any life that is even as good as nonexistence.) This isn't because good lives are somewhow worse than nonexistence. They are neither better, nor worse, nor equally good - they are incommensurable. ${ }^{7}$

Asymmetric comparativism is compatible with the intuitive neutrality of creating good lives, because the creation of such lives does not, according to asymmetric comparativism, make things better for those who live them. And, according to asymmetric comparativism, creating bad lives can wrongfully harm those created by making them worse off than if they never existed. I take this to be reason enough to at least consider asymmetric comparativism.

In my experience, many outsiders to population ethics find asymmetric comparativism plausible. Surprisingly, however, the view has received little attention in the philosophical literature. ${ }^{8}$ I suspect this is because it is widely assumed that if it cannot be better for a person to live a good life than not to exist, this must be explained by some general barrier that makes it impossible to compare a person's life with her nonexistence. This assumption makes it hard to see how asymmetric comparativism could possibly be true: how could a bad life be worse than nonexistence, if a good life cannot be better? My primary aim in this paper is to sketch an answer to this question.

My aim is primarily explanatory, not dialectical. If you are not already sympathetic to the judgments that challenge symmetric comparativism and noncomparativism, I doubt that there is any valid argument for asymmetric comparativism from premises you would independently accept. My aim, instead, is to explain how asymmetric comparativism could possibly be true. Only with such an explanation in hand can we be in a position to assess its ultimate plausibility in comparison to the standard views.

To focus on this task, I set aside existing arguments for the standard views. Most importantly, I will not consider the most common argument for noncomparativism, pressed most influentially by Broome (1993). According to the argument, it is worse for a person to exist than not to exist only if, had she never existed, that would have been better for her than if she did. But, if she had never existed, there would be no her for whom that could be better. Thus, according to the argument, it cannot be worse for a person to exist. Obviously, if this or any other argument for noncomparativism is sound, then asymmetric comparativism is false, but so is symmetric comparativism. I want to focus here on challenges to asymmetric comparativism that could, in principle, be pressed by both noncomparativists and symmetric comparativists alike. The literature already contains many objections to the Broomean argument, which I mention in a note. ${ }^{9}$ For the rest of the paper, I set it aside, along with other general worries about the coherence of comparing existence and nonexistence. I am not certain that such comparisons are ever true. But I am not persuaded by the most influential argument against their coherence. And we should want to know the space of plausible views and their ethical implications if they are indeed coherent. 
My account of asymmetric comparativism begins with another asymmetry, regarding the (dis)value of early death. I argue that a plausible explanation of this early death asymmetry can be extended to support asymmetric comparativism. I conclude by considering and rejecting the charge that asymmetric comparativism has unacceptably antinatalist implications.

\section{The Early Death Asymmetry}

Suppose that a large asteroid might hit the earth tomorrow, and that everyone alive will die immediately if it does. Consider two human beings, Ziggy and Addie. Ziggy has just begun to exist; I will imagine that he is a zygote. (I assume that the life of a human being begins at conception. If you doubt that zygotes are human beings or even living things, you can imagine Ziggy to be a late-term fetus or newborn infant instead.) Addie is twenty years old. If the asteroid doesn't hit tomorrow, both Addie and Ziggy will have very good lives and die at the age of eighty.

If the asteroid hits tomorrow, for whom would that be worse: Ziggy or Addie? Many of us think it would be worse for Addie than it would be for Ziggy. We think this even though Ziggy's death would deprive him of twenty more years of happy life than Addie's. This judgment is controversial, but many people find it compelling. ${ }^{10}$ If you do not share it, you can take the discussion that follows in a conditional spirit - i.e., of what might be true if Addie's death is worse than Ziggy's. (My account of asymmetric comparativism won't ultimately presuppose the correctness of this judgment, despite its role in motivating the view.)

Suppose next that if the asteroid doesn't hit, Ziggy's and Addie's lives will be miserable - filled only with horrible, unmitigated suffering until they die at the age of eighty. In this case, if the asteroid hits, that would be a good thing for both Ziggy and Addie. For whom would it be better? It seems to me clearly better for Ziggy. This is because Ziggy's death would spare him twenty more years of suffering.

There is an intuitive asymmetry here. Define a very early death as a death that occurs shortly after a person begins to exist. These may include neonatal deaths, abortions, miscarriages, and nonimplantations, depending on one's views about when life begins. According to

\section{The Early Death Asymmetry:}

(1) Very early deaths that deprive people of happy futures are not as bad for their victims as the deaths of older people who would have had shorter, but still happy, futures. But

(2) Very early deaths that save people from miserable futures are better for their beneficiaries than the deaths of older people who would have had shorter, but still miserable, futures. 
The first half of this asymmetry has been widely discussed. But extant attempts to explain (1) make it hard to explain (2).

For example, the leading account of (1) appeals to time-relative interests (McMahan 2002). A person's interest, relative to some initial time, in the value of her future is the value of her future weighted by the psychological unity-i.e., degree of overlap in psychological connections-between herself at the initial time and her future self. Ziggy tomorrow shares no psychological connections with his future self. So, even if his death tomorrow would deprive him of future happiness, he has little to no tomorrow-relative interest in that future happiness. Addie is much more strongly connected to her future self, so she has a greater tomorrow-relative interest in her future. If the (dis)value of an event for a person is a function of the person's interests relative to the time at which it occurs, then Addie's death tomorrow is worse than Ziggy's. But suppose that Ziggy and Addie would live miserable lives. Addie would seem to have much stronger tomorrowrelative interest in avoiding future suffering than Ziggy. So Addie's fortunate death would seem to be better than Ziggy's, contrary to (2).

There may be ways of modifying the time-relative interests account to capture both halves of the early death asymmetry. ${ }^{11}$ I won't consider them here. I want to focus instead on an alternative account of the early death asymmetry, which can be extended to support asymmetric comparativism. But, before doing that, let me explain why we might even expect the early death asymmetry to be relevant to asymmetric comparativism.

If the first half of the early death asymmetry is correct, then it is natural to think that the badness of very early, good-life-depriving death increases with length of life lived. For example, the death of a newborn infant who would have had a good life seems worse than the death of a late-term fetus who would have had a good life, which seems worse than the death of a zygote who would have had a good life. (Many who are attracted to the early death asymmetry would, I suspect, judge that the death of a zygote that has just been conceived is not very bad for her, if bad for her at all.) On this picture, it is natural to think that, when length of life approaches zero-i.e., nonexistence-it is no longer bad at all for the person not to exist, as asymmetric comparativism predicts. And, if the second half of the early death asymmetry is correct, then it is natural to think that the goodness of very early, bad-life-sparing death increases with the quantity of bad life spared. But, setting aside metaphysical scruples about comparing existence with nonexistence, it seems at least somewhat strange to think that it is better for a would-be-miserable person to live as little of her life as possible, but not better for her not to live at all. This suggests that, if we are independently attracted to the early death asymmetry, we might have reason to be asymmetric comparativists. ${ }^{12}$

Of course, this falls far short of a decisive argument from the early death asymmetry to asymmetric comparativism; it's only meant to motivate our discussion of the former in the course of studying the latter. With that 
motivation in place, I would now like to offer a possible account of the early death asymmetry.

\section{The Conditional Desire Asymmetry}

My account of the early death asymmetry appeals to the idea of conditional goods, which is based on the notion of conditional desires. ${ }^{13}$

Williams (1999) distinguishes between those of a person's desires that are conditional on her being alive, and those that are not. For example, my desire to have a cavity filled is plausibly conditional on my being alive. ${ }^{14}$ I want my cavity to be filled if I am alive next week. But it's not the case that I want my cavity to be filled even if I'm dead next week. By contrast, my desire that my children flourish is not conditional on my being alive. I want my children to flourish even after I die.

It will help to introduce some terminology. Following McDaniel and Bradley (2008), I will assume that all desires can be understood on the model of conditional desires, as having both an object (e.g., that my cavity is filled) and a condition (e.g., that I continue to live). Sometimes the condition is trivial, and that accounts for the phenomenon of seemingly unconditional (or "categorical") desire, when the object is desired no matter what else is the case. If you desire that $p$ on the condition that $q$, then your desire is satisfied just in case $p$ and $q$ are both true, frustrated just in case $q$ is true but $p$ is false, and cancelled just in case $q$ is false.

The notion of conditional desire has proved difficult to analyze, and I won't try to analyze it here. I suspect that there may be several kinds of attitude in the vicinity, none of which uniquely deserves the name "conditional desire." The notion I'm interested in, however, can be clarified by highlighting its relation to preferences. It is plausibly necessary (at least, for rational agents) that one desires that $p$ on the condition that $q$ only if, ceteris paribus, one prefers the material conditional $q \supset p$ to be true rather than false. (The "ceteris paribus" clause is meant to bracket the independent desirability of the condition and the object. This is needed to accommodate the possibility that one has other, conflicting desires or preferences, which might prevent one from having an allthings-considered preference for $p \supset q$ over its negation. ${ }^{15}$ ) This means that, ceteris paribus, one prefers the conditional desire's satisfaction to its frustration, and its cancellation to its frustration, but it leaves open one's preference between satisfaction and cancellation. Although one might prefer satisfaction to cancellation (or vice versa) on other grounds, the conditional desire itself is silent with respect to this preference, and is compatible with having no preference at all between these alternatives. Suppose, for example, that I desire to have a beer on the condition that I continue to want one. On the proposed connection between conditional desire and preference, I should prefer either not wanting a beer (cancellation) or wanting and having one (satisfaction) to wanting but not having 
one (frustration), but need not prefer wanting and having one (satisfaction) to not wanting one (cancellation). ${ }^{16}$

On this view about the relation between preference and conditional desire, there is a kind of asymmetry in our rational attitudes towards the frustration and satisfaction of a conditional desire: rationality requires that frustration be dispreferred to cancellation, but does not require satisfaction to be preferred to cancellation. Call this the conditional desire asymmetry.

The conditional desire asymmetry might be rejected in either of two ways. On the one hand, some might wonder why the satisfaction of a conditional desire need not be preferred to its cancellation. The answer is that, if satisfaction were preferred to cancellation, there would be little to distinguish conditional from apparently unconditional (or conditional-on-triviality) desires. For example, I do not want to die next week. But, if I do, I want my house to be given to my children. Clearly I need not prefer the satisfaction of this conditional desire (my dying next week and my children inheriting my house) to its cancellation (my survival).

On the other hand, we might wonder why frustration should be dispreferred to cancellation. My primary reason for thinking this is that it follows from the simple connection between conditionally desiring and preferring a conditional, and because this simple connection will bear explanatory fruit in what follows. But another reason is that, in general, we treat the frustration of a desire-even a conditional one - as something to be avoided. Suppose, for example, that I want to scratch my nose on the condition that it itches. ${ }^{17}$ Intuitively, what I want not to happen is that my nose itches but I can't scratch it. If I could choose between my nose not itching and its itching without my scratching it, I should rationally prefer the former (at least, if other things are equal).

The conditional desire asymmetry draws a simple connection between preference and conditional desire: rationality requires that if you have a conditional desire, then, ceteris paribus, you prefer the corresponding material conditional to be true rather than false. Since both satisfaction and cancellation are ways of making the corresponding conditional true, this means that you prefer both satisfaction and cancellation to frustration. But it leaves open your preference between these two ways of making the conditional true. Again, I do not claim that the account just offered captures the only phenomenon that philosophers have called "conditional desire," or that people express in natural language with desire reports embedded under conditionals. But I take it to be a notion whose good standing is suggested by the examples given above and, more importantly, by the work to which we put it below.

\section{The Conditional Good Asymmetry}

If there are conditional desires, then we should expect there also to be conditional goods: things that are worth wanting, either tout court or for someone's 
sake, only on some condition. I will soon give some examples. For now, I just want to explain how conditional goods relate to conditional desires.

On many views, there is a tight connection between goodness and betterness on the one hand, and desire and preference on the other. ${ }^{18}$ On such views, it is good for a person that $p$ if and only if it is fitting, or rationally required, required by reasons, or one ought_-I'll just use required as a placeholder for the correct normative property in the vicinity - to desire that $p$ for that person's sake; and, similarly, $p$ is better for a person than $q$ if and only if it is required to prefer $p$ to $q$ for that person's sake. Some philosophers analyze value in terms of such fitting attitudes, but we can accept some biconditional in this neighborhood even if we take value to be unanalyzable.

Given some such connection between value and desire, we can understand conditional goods as follows: $p$ is good for a person on the condition that $q$ just in case it is required to conditionally desire that $p$, for that person's sake, on the condition that $q$. And, given the conditional desire asymmetry, desiring that $p$ on the condition that $q$ requires (ceteris paribus) that one prefer $q \supset p$ to be true rather than false. We should therefore expect that if $p$ is good for a person on the condition that $q$, then (ceteris paribus) it should be required to prefer, for that person's sake, that $q \supset p$ be true rather than false. And if it is required to prefer $q \supset p$ to $\neg p \wedge q$ for a person's sake, then $q \supset p$ must be better for her than $\neg p \wedge q$. To extend McDaniel and Bradley's terminology for conditional desires to conditional goods (somewhat unhappily, but for simplicity), the satisfaction or cancellation of a conditional good is better for a person than its frustration.

This, again, leaves open the comparison between satisfaction and cancellation: if $p$ is good for a person on the condition that $q$, then how do $p \wedge q$ and $\neg q$ compare? For all we've said, it could be permissible to have either preference. Given our connections between value and preference, this means that - at least, if other things are equal-neither is better than the other. For if one were better than the other, then it would be required to prefer one to the other.

Does this mean that the two are equally good? This depends on how one understands the connection between equal goodness and permissible preference. Following Rabinowicz (2008, 2012), I take it that two things are equally good just in case one is required to be indifferent between them. On Rabinowicz's view, which I'll take for granted here, if it is permissible to prefer either of two things to the other, then those things are not equally good but incommensurable. ${ }^{19}$ This suggests that the satisfaction and cancellation of a conditional good are incommensurable, because one is not required to prefer satisfaction to cancellation or vice versa.

Summing up, the conditional desire asymmetry and our connections between value and desire make plausible what we can call the conditional good asymmetry: the satisfaction of a conditional good is better for a person than its frustration, which is worse for her than its cancellation, but satisfaction need not be either better or worse for her than, or just as good for her as, cancellation. This asymmetry, I suggest, can help us explain the early death asymmetry. 


\section{The Conditional-on-Maturity Claim}

My account of the early death asymmetry appeals to two claims. The first is the conditional good asymmetry, which we motivated by appealing to the conditional desire asymmetry and some plausible connections between value and desire. The conditional desire asymmetry was, in turn, motivated by a simple necessary connection between conditional desire and preference: namely, that to have a conditional desire, one must (ceteris paribus) prefer the corresponding material conditional to be true rather than false, but need not have any preference between its antecedent's truth and its falsity.

The second claim is that most important ingredients of a person's good are conditional goods - in particular, that they are only good for a person conditional on some proposition or other that normally holds of mature human beings but does not hold of very young ones, such as zygotes, infants, and fetuses. Call this the conditional-on-maturity claim. I will try to motivate the conditional-onmaturity claim by considering some plausible ingredients of prudential value and explaining how they might satisfy the conditional-on-maturity claim.

First, consider the value of satisfying our desires or other, more sophisticated attitudes or complexes of attitudes - e.g., plans, goals, hopes, ambitions, intentions, expectations, or values. (For simplicity, I will call these desire-like attitudes.) On many conceptions of the good, it is better for a person, other things being equal, if such attitudes (or some important complex or proper subset of them) are satisfied than if they are frustrated. But, many people believe, the acquisition and satisfaction of such an attitude is, by itself, no better for a person than never having had such an attitude. ${ }^{20}$ Suppose, with Parfit $(1984,497)$, that I give you a costless drug which has only one effect: it makes you want to have more of the drug (or to value the drug, or whatever our favored attitude is towards the drug). It may be better for you to have this desire satisfied than frustrated, given that you have it. But the satisfaction of this desire is, arguably, no better for you than if you had never wanted it to begin with. ${ }^{21}$

This kind of judgment about the absence of desire can be explained by the idea that the satisfaction of a desire-like attitude is conditionally good for a person on the condition that she has ever had that attitude. Given the conditional good asymmetry, this implies that the satisfaction of such an attitude is better for the person who has it than its frustration, which is worse for her than never having had the attitude, but that never having had the attitude is, ceteris paribus, neither better nor worse for her than (nor just as good for her as) its satisfaction.

This would satisfy the conditional-on-maturity claim because infants, fetuses, and zygotes do not have rich desire-like attitudes to be frustrated by their early deaths. Older children and adults, by contrast, have such attitudes in spades. Thus, the death of an infant, fetus, or zygote who lacks desire-like attitudes but would have acquired and satisfied them is - at least, with respect to the value of satisfying desire-like attitudes — not as bad as the death of a mature human being 
whose death frustrates her desire-like attitudes. But the death of an infant, fetus, or zygote whose future desire-like attitudes would have been frustrated is - at least, in this respect-better than the death of a mature human being whose death prevents lesser desire frustration.

Second, consider perfectionist goods. Welfare perfectionists believe that a thing's good consists in the excellent functioning, development, or exercise of certain special capacities (e.g., ones that are characteristic to the kind of thing it is). The relevantly characteristic capacities might be determined in different ways, but the capacities for human beings tend to include both theoretical and practical rationality.

Perfectionist goods might satisfy the conditional-on-maturity claim if the excellent functioning of an individual's special capacities is no better for her than the total absence of those capacities. On this view, what's good for an individual is the excellent functioning of her special capacities, given that she has them, to at least some minimal degree; it's not good for an individual to have those capacities so that they can function excellently. For example, it seems reasonable not to lament, for the sake of lower animals, that they lack the special capacities that are characteristic of human beings. We want such animals to develop and exercise their distinctive capacities; we need not want them to have entirely different capacities, even if they could (except insofar as doing so would help them develop and exercise their own distinctive capacities). ${ }^{22}$

This view about perfectionist goods can help to explain the early death asymmetry because a zygote, fetus, or newborn infant has little, if any, capacity for rational thought, or of anything else. ${ }^{23}$ So although his death deprives him of a life in which he exercises the relevant capacities, that is not much of a loss for him, compared to the near-total absence of those capacities. But the poor functioning of those capacities, if he suffers, seems worse for him than the neartotal absence of those capacities. So, his miserable survival would be worse for him than the less miserable (because shorter) survival of an adult, even though his unfortunate death would not be as bad for him as the unfortunate death of an adult. In the case where both futures would be bad, the zygote's death is better than the older person's - at least, with respect to perfectionist goodsbecause the cancellation of such goods is better than their frustration, and the zygote would go on to experience more frustration than the older person. In the case where both futures would be good, the zygote's death is not as bad as the older person's, even if the zygote's future would contain greater satisfaction of perfectionist goods, because the cancellation of such goods is no worse than their satisfaction. ${ }^{24}$

Third, consider the value of sophisticated or "higher" pleasures-e.g., the pleasure of solving complex puzzles, or of deeply appreciating some work of art or beautiful landscape. Such pleasures might only be good for a person on the condition that she has the capacity to enjoy them. On this view, what's good for a person is that a person engages in some supremely enjoyable activity, given that she has the capacity to enjoy that activity; it's not good for a person to 
have the capacity to enjoy those activities so that she can enjoy them. One might make similar claims about knowledge, loving relationships, and other plausible ingredients of a good life. For example, it might be good for a person to know that $p$ only on some condition that very young human beings lack - e.g., that she has ever wondered whether $p$, or that she has some doxastic attitude towards $p$, or can understand whether $p$. Friendships and other loving relationships might be good for a person only on the condition that she has the capacity to love. These claims could help explain why, even if we could make rocks, plants, and other nonsentient beings able to feel pleasure, gain knowledge, or form loving relationships, we would (intuitively) have no reason to prefer for their sakes that they have these abilities than that they lack them.

Obviously, I cannot argue that the conditional-on-maturity claim is true on every plausible view about prudential value. I am content to conclude that it is plausible on some such views. I suspect that proponents of views that mesh poorly with the conditional-on-maturity claim - most obviously, Benthamite hedonism and unsophisticated desire-satisfaction views - would be independently inclined to reject the early death asymmetry. Again, my goal here is to explain how the early death asymmetry could possibly true, and my explanation appeals to the possibility of views that satisfy the conditional-on-maturity claim. I would take it as some confirmation for my account if these principles - the early death asymmetry and the conditional-on-maturity claim - stand or fall together.

Let's sum up. My account of the early death asymmetry appeals to two claims. One is the conditional-on-maturity claim that most important ingredients of well-being are only good for a person on some condition or other that does not normally hold of very young human beings. The other is the conditional good asymmetry, which says that the satisfaction or cancellation of a conditional good is better for a person than its frustration, but that its satisfaction is no better for her than its cancellation. These two claims can together explain why the very early deaths of zygotes, fetuses, and newborn infants who would have had happy lives are not as bad as the deaths of mature human beings with happy lives, while the very early deaths of those who would have had miserable lives are worse than the deaths of mature human beings with miserable lives. The explanation is that very early deaths merely cancel, rather than frustrate, the most important aspects of a person's good, and that cancellation (from very early death) is better than frustration (from living a long, miserable life) but no worse than satisfaction (from living a long, happy life). Of course, there may still be ways in which the very early deaths of those who would have lived happy lives are quite bad, and indeed worse than the deaths of mature human beings, because their deaths still deprive them of goods whose conditions they satisfy (including the trivial case of unconditional goods, if there are any). This may be true, for example, of simple pleasures. But, on the present picture, these respects are not important enough to overcome the more important ways in which their deaths are simply incommensurable with their survivals. 
This account of the early death asymmetry suggests an account of asymmetric comparativism, which I provide in the next section.

\section{The Conditional-on-Existence Claim}

My account of asymmetric comparativism appeals to the conditional good asymmetry and a generalization of the conditional-on-maturity claim. According to the conditional-on-existence claim, everything that is good for a person is conditional on some proposition or other which entails that she exists. ${ }^{25}$

The conditional-on-existence claim and the conditional good asymmetry can be used to explain asymmetric comparativism. According to the conditional-onexistence claim, the kinds of things that make a person's life worth living are only good for her on some condition that entails her existence. Thus, if she never exists, then all such goods are cancelled. So, according to the conditional good asymmetry, her existence is - with respect to every component of her wellbeing - no better for her than her nonexistence, because satisfaction is no better than cancellation. If her existence is in no way better for her, then her existence cannot be better for her overall. But if someone exists with a purely miserable life, then her life must contain the frustration of many conditional goods. That is worse for her than nonexistence, which would merely cancel those goods.

Of course, some miserable lives have good elements - i.e., goods that are satisfied. But it seems plausible that, for any miserable life containing some goods, there is some possible life that contains nothing good but which, because it contains fewer or less severe frustrations, would be better. If every purely miserable life, containing only frustration, is worse than nonexistence-because worse in every respect - then every miserable life with good elements will also be worse than nonexistence. So the existence of miserable lives with good elements poses no threat to asymmetric comparativism, and more generally we can consider only lives that are purely good or bad.

Why might we accept the conditional-on-existence claim, beyond its possible role in explaining asymmetric comparativism? The conditional-on-existence claim seems to me supported by plausible generalizations of the intuitions that motivated the conditional-on-maturity claim.

Consider again the example of perfectionist goods. The intuition that motivated the conditional-on-maturity claim for perfectionist goods was that the excellent functioning of a being's special capacities is only good for her on the condition that she has those capacities, at least to some minimal degree. Some welfare perfectionists might not share this intuition. They might think that a being only needs to be a member of a kind that is characertized by having certain capacities for the excellent functioning of those capacities to be good for her. This thought can still explain why, for example, we lack reason to regret, for the sake of rocks, plants, and other nonsentients, that those things don't have the kinds of capacities whose excellent functioning makes our lives go well. But 
the relevant condition here - that the being is a member of a certain kind - still requires her to exist. So this plausible weakening of the intuition, which fails to satisfy the conditional-on-maturity claim, nonetheless satisfies the conditionalon-existence claim.

Next return to the example of hedonic goods. The relevant instance of the conditional-on-maturity claim was that sophisticated, higher pleasures are only especially good for a creature on the condition that she can enjoy those pleasures, perhaps in certain ways. Many hedonists might not share this intuition. But such hedonists might still plausibly think that pleasure in general is only good for a being on the condition that she is, or has ever been, conscious or sentient. This thought can explain why, on a hedonist picture, we might lack reason to regret for the sake of rocks, plants, and other nonsentients, that those things do not feel pleasure. They do not feel pleasure because they are not conscious, and pleasure is only good for a thing on the condition that it is or has ever been conscious. And this condition still requires the thing to exist. So, again, this plausible weaking of the intuition, which fails to satisfy the conditional-on-maturity claim, still satisfies the conditional-on-existence claim.

Similar claims apply to the other kinds of goods we have considered. In the case of desire satisfaction, we considered the view that the obtaining object of a person's desire is only good for her on the condition that she has ever desired it. Even if that is not so, we might reasonably think that this good is conditional on a person's having any conative or desire-like states whatsoever-which, again, requires that she exists. In the case of knowledge, we considered the view that it's good for a person to know that $p$ only if she has ever wondered whether $p$ or has had some doxastic or inquiring attitude towards $p$ (or some suitably similar proposition). Even if we reject that view, we might reasonably think that this good is conditional on a person's having any cognitive or inquisitive attitudes whatsoever - which, again, requires that she exists.

As with the conditional-on-maturity claim, I cannot hope to consider every possible ingredient or conception of prudential value and identify a plausible instance of the conditional-on-existence claim. But I hope the above remarks illustrate how, on some plausible views, the conditional-on-existence claim may seem attractive - indeed, more attractive than the conditional-on-maturity claim. I suspect, again, that those who find the conditional-on-existence claim unattractive will be independently inclined to reject asymmetric comparativism and the intuitions that motivated our interest in asymmetric comparativism, so that these two views tend to stand or fall together. That is progress.

That is my account of how asymmetric comparativism could possibly be true. It would be true if all ingredients of a person's good were conditional on her existence, and if conditional goods obey the conditional good asymmetry. The conditional-on-existence claim is motivated by a plausible generalization of the intuitions supporting conditional-on-maturity claim, and the conditional good asymmetry is motivated by simple connections between conditional desire, preference, and value. The conditional-on-maturity claim and the conditional good 
asymmetry also help to explain the early death asymmetry, which should seem independently attractive to those who like asymmetric comparativism. Asymmetric comparativism is therefore part of a network of mutually supporting views each of which has some independent plausibility. One could of course accept some but not all of these views, and none of them is obvious or uncontroversial. But I take the explanatory connections between them to enhance the attractiveness of the overall package.

\section{Antinatalism}

With this package on the table, I want to conclude by considering an objection to asymmetric comparativism.

Perhaps the most obvious objection to asymmetric comparativism, and to the more general package of views I have sketched, is that it might seem to have unacceptably antinatalist implications. The objection can arise in at least three different settings. I'll mention all three, because doing so will help to identify a lesson of more general importance. ${ }^{26}$

The first setting is the creation of many lives. Suppose that we could bring some large number of people into existence, all of whom would be happy except for one person whose life would be very nearly worth living. And suppose, unrealistically, that this act would affect no one else. Intuitively, the act is permissible, at least if the number of happy people is sufficiently large. But, according to asymmetric comparativism, if we bring into existence many happy people and some miserable people, this act would be worse for some person (the unhappy one) and no better for anyone else. And it might seem impermissible to do what is worse for some and no better for anyone, at least when other things are equal. So, asymmetric comparativism might seem to imply, counterintuitively, that this act is wrong.

The second setting is the creation of a single life under uncertainty. Suppose that we could bring a single person into existence, whose life would almost certainly be wonderful but might, with some probability, not be worth living. And suppose, again, that this act would affect no one else. Intuitively, this act is permissible, and would not be worse for the person who would be created. But, according to asymmetric comparativism, there is some probability that this act would be worse for the person created, and there is no probability that it would be better for her. And an act that might be worse for a person and is certainly not better for her might seem worse for her ex ante. And it might seem impermissible to do what might be worse for someone and is certainly better for no one. So, asymmetric comparativism might seem to imply, counterintuitively, that this act is worse (ex ante) for the person created and impermissible.

The third setting is the creation of a single life under certainty, where the life is worth living but contains both good and bad components. According to my account of asymmetric comparativism, this life would be in various ways worse 
Table 1. A Pseudodominance Cycle

\begin{tabular}{cccc}
\hline & $i$ & $j$ & $k$ \\
\hline$A$ & $x$ & $x+$ & $y$ \\
$B$ & $x+$ & $y$ & $x$ \\
$C$ & $y$ & $x$ & $x+$ \\
\hline
\end{tabular}

than nonexistence, and in no way better. This is because it would contain both the frustration and satisfaction of various goods that are conditional on the person's existence. According to the conditional good asymmetry, the frustrations are ways in which the life would be worse than nonexistence, but the satisfactions aren't ways in which it would be better. But if every happy life that contains some bad things is in some ways worse than nonexistence, and in no ways better, then every such life might seem worse than nonexistence. So, my account of asymmetric comparativism might seem to imply, counterintuitively, that every such life is worse than nonexistence.

The objection assumes, in all three settings, a kind of dominance principle. Suppose that some value depends on various dimensions, along which things can be better or worse. Say that one thing weakly dominates another, with respect to that value, just in case it is better along some dimension of that value, and at least as good along all other dimensions. One thing pseudodominates another, with respect to that value, just in case it is better along some dimension of that value, and no worse along any other dimensions of that value. In the many-life setting, the relevant dimensions are the good of each person. In the uncertain single-life setting, they are the person's good in each epistemically possible state of the world. In the certain single-life setting, they are the different aspects of the person's good. The objection assumes, in all three settings, that being pseudodominated is a sufficent condition for worseness or impermissibility.

However, in the presence of incommensurability (due, e.g., to the conditional good asymmetry), this assumption is false. This is because, under incommensurability, the pseudodominance relation can contain cycles. This is a familiar point in population ethics (Temkin 1987; see also Nebel 2019, 327), but it is of quite general importance. Consider the structure depicted in table 1 , where $i, j$, and $k$ are dimensions of some value; $A, B$, and $C$ are bearers of that value; and $x, x+$, and $y$ are values instantiated along the relevant dimensions, where $x+$ is better than $x$, and $y$ is incommensurable with $x$ and $x+$.

In table $1, B$ is better than $A$ with respect to $i$, and worse than $A$ in no respect, so $B$ psuedodominates $A$. $C$ is better than $B$ with respect to $k$, and worse in no respect, so $C$ pseudodominates $B$. And $A$ is better than $C$ with respect to $j$, and worse in no respect, so $A$ pseudodominates $C$. Thus, if being pseuodominated were a sufficient condition for worseness or impermissibility, then all options would be impermissible or worse than some alternative. And that is impossible. ${ }^{27}$ 
Asymmetric comparativists can therefore avoid the charge of antinatalism, in all three settings, by denying that pseudodominated options are impermissible or worse with respect to the value in question.

Of course, I haven't identified a complete theory in population ethics that includes asymmetric comparativism and lacks these antinatalist implications. There are several possibilities for such a theory. ${ }^{28}$ But, since considering those possibilities would lead to a lengthy discussion of more general problems in population ethics, I leave that discussion for another occasion. ${ }^{29}$

\section{Notes}

1. The question is at least as old as the Babylonian Talmud, which reports that the rabbis of Beit Shammai and Beit Hillel debated, voted, and decided that "it would be better for a person not to be created than to be created" (Eruvin 13b, trans. Berel Dov Lerner 2010, 431).

2. See Adler (2009); Arrhenius and Rabinowicz (2015); Fleurbaey and Voorhoeve (2015); Holtug (2001); Roberts (2003).

3. See Blackorby, Bossert, and Donaldson (2005); Broome (2004); Bykvist (2007); Dasgupta (1994); Heyd (1988); McMahan (2013).

4. See Bennett (1978); Frick (2014); Narveson (1967).

5. Symmetric comparativism also makes it very hard to avoid Parfit's (1984) repugnant conclusion (see Arrhenius 2015; Nebel 2019).

6. The qualifications are meant to accommodate the possibility that one can be wronged by virtue of being harmed without having been made worse off, all things considered, than one would or could have been otherwise (for examples, see Harman 2004; Shiffrin 1999). But, for reasons to doubt that possibility, see Boonin (2014 ch. 3).

7. This claim distinguishes asymmetric comparativism from the "antifrustrationist" view of Fehige (1998), on which a life with no unsatisfied preferences is just as good for a person as nonexistence. We might classify Fehige, and perhaps Benatar (2006), as symmetric comparativists who deny that there are, or even could be, lives worth living, because nonexistence is at least as good as every possible life.

8. One notable exception is Arrhenius (2009), who dismisses the view for the reason stated in the next sentence. I mention asymmetric comparativism in Nebel (2019, 336) but do not discuss its possible foundations.

9. In Nebel $(2019,332)$, I argue that the Broomean argument has unacceptable implications for the evaluation of uncertain prospects. Arrhenius and Rabinowicz (2015) argue that, so long as a person actually exists, states of affairs in which she doesn't exist can be better or worse for her, even though they wouldn't be better or worse for her if they obtained. Fleurbaey and Voorhoeve (2015) argue that, even if a person never lived, she would have been something - namely, a merely possible person (cf. Parfit 2017, 133; Williamson 2013) -for whom that could have been better or worse. Another response would be to claim that things can be better or worse for $S$ even if there is no such being as $S$, on the grounds that property instantiation does not require being (see, e.g., Bacon 2013 on empty 
names). Though it seems independently plausible that there are no merely possible people, and that property instantiation requires being, the combination of these views is particularly hard to sustain (see, e.g., Goodman 2016; Dorr 2016; Fritz and Goodman 2017).

10. Proponents include Belshaw (2005) and McMahan (2002). For critique, see Bradley (2008).

11. McMahan $(2015,2019)$ supplements the time-relative interests account with an independent asymmetry on which "there is a reason to prevent an individual from suffering even if it has no present interest in avoiding it" (2015, p. 80), but no such reason (or weaker reason) to provide them with later goods that they lack present interest in acquiring. See also Thomas (2016 ch. 4), who modifies the time-relative interests account in sophisticated ways inspired by views in population ethics.

12. See also Pummer (2019), who argues, from the slight nonevaluative difference between never existing and existing for very little time, to a kind of continuity between the value of survival and the value of coming into existence.

13. On conditional desires, see McDaniel and Bradley (2008); Parfit (1984, sec. 59); Williams (1999 ch. 6). The notion of conditional good is suggested in the context of population ethics by Bader (manuscript), Broome (2004), and Dasgupta (1988). Frick (2014) appeals to conditional reasons. Note that, despite my focus on desire in this section, my account of the early death asymmetry need not place any weight on the value of desire satisfaction, and is distinct from the "categorical desire account" of the badness of death (for critique, see Bradley and McDaniel 2013).

14. The example is due to Scheffler (2013).

15. For example, Edgington (2014) supposes that she has a small chance of winning some prize and desires that "if I win the prize $(W)$, you tell Fred straight away (T)." She does not prefer $W \supset T$ to be true rather than false. But this is because, independently, she wants the condition $W$ to be true. The "ceteris paribus" clause is intended to bracket this kind of case and, more generally, the independent desirability of the conditions. If one independently had no desire for the condition $W$ to be true, then, I suggest, one would prefer $W \supset T$ to be true rather than false - at least, if one has a conditional desire, in the sense I'm interested in, with condition $W$ and object $T$. (An alternative interpretation is that one's desire in this case is really unconditional but is expressed using a conditional only because $T$ entails $W$, which is not known to be true; so expressing a desire that $T$ would infelicitiously presuppose $W$.)

16. Note that this connection between preference and conditional desire is not an analysis of conditional desire, or even a sufficient condition. Perhaps one could prefer some material conditional to be true rather than false without desiring its consequent conditional on the antecedent.

17. This example is due to McMahan $(1998,496)$.

18. See, e.g., Broad (1933); Ewing (1939); Parfit (2011); Scanlon (1998).

19. More specifically, for Rabinowicz, they are on a par (see Chang 2002). But the distinction between parity and incommensurability more generally won't matter for our purposes.

20. See, e.g., Barry (1989); Fehige (1998); Handfield (2011); Singer (2011).

21. For critical discussion of Parfit's example, see Heathwood (2017). 
22. Although see Lin (2017), who suggests that theoretical contemplation may be good for dogs.

23. Intrestingly, Hurka (1993 ch. 4) concludes that fetuses and infants are not humans because they lack rational capacities, which (according to his Aristotelian perfectionism) are essential to humans. So there is some precedent for perfectionists to hold that the good of a fetus is distinct from the good of a mature human being (although, strictly speaking, Hurka's perfectionism is not a theory of well-being).

24. This instance of the conditional-on-maturity claim may seem incompatible with the intuition that it is tragic for, say, a would-be musical genius to die as a child, before she has an opportunity to develop her talents. But even a child, however young, has various capacities that would be frustrated by death-e.g., the higher-order capacity to acquire musical (or other) talents, or to develop rational capacities more generally. By appealing to capacities to acquire further capacities, perfectionists can judge that early death is always at least somewhat bad for the one who dies, while still maintaining that the deaths of zygotes are less bad than those of children and adults, who have more and greater capacities.

25. Broome (1999 ch. 15) explores the possibility that "all the goods in a person's life are conditional on the person's existence.” But he finds it incoherent, I think, because he overlooks the possibility of the conditional good asymmetry.

26. Although I frame these objections as challenges to asymmetric comparativism, they can be modified to challenge my account of the early death asymmetry as well.

27. Of course, some philosophers think there can be betterness cycles (Rachels 1998; Temkin 1996). I discuss their arguments in Nebel (2018).

28. For example, Rabinowicz (2009)'s neutral-range utilitarianism with the neutral range including all nonnegative welfare levels, and versions of the restricted average view considered in Nebel $(2019,337)$.

29. I am grateful to Johann Frick, Jeremy Goodman, Ben Holguín, Eden Lin, Sam Scheffler, and Jake Zuehl for helpful comments and discussion.

\section{References}

Adler, Matthew. (2009). "Future Generations: A Prioritarian View." George Washington Law Review 77: 1478. http://heinonline.org/HOL/Page?handle=hein.journals/gwlr77\& $\mathrm{id}=1488 \& \mathrm{div}=\&$ collection $=$ journals.

Arrhenius, Gustaf. (2009). "Can the Person Affecting Restriction Solve the Problems in Population Ethics?" In Harming Future Persons, edited by M. A. Roberts and David Wasserman, 289-314. Ashgate.

(2015). "The Affirmative Answer to the Existential Question and the Person Affecting Restriction." In Weighing and Reasoning: Themes from the Philosophy of John Broome, edited by Iwao Hirose and Andrew Reisner. Oxford: Oxford University Press. https://doi.org/10.1093/acprof:oso/9780199684908.003.0009.

Arrhenius, Gustaf, and Wlodek Rabinowicz. (2015). "The Value of Existence." In The Oxford Handbook of Value Theory, edited by Iwao Hirose and Jonas Olson. Oxford University Press.

Bacon, Andrew. (2013). “Quantificational Logic and Empty Names.” Philosophers' Imprint 13 (24): 21. 
Bader, Ralf M. n.d. "Person-Affecting Population Ethics." Unpublished manuscript.

Barry, Brian. (1989). "Utilitarianism and Preference Change." Utilitas 1 (02): 278-82. https://doi.org/10.1017/S0953820800000273.

Belshaw, Christopher. (2005). "Which Deaths Are Worse?" In 10 Good Questions About Life and Death, 44-58. Blackwell Publishing Ltd. https://doi.org/10.1002/9780470775035.ch4.

Benatar, David. (2006). Better Never to Have Been: The Harm of Coming into Existence. Oxford: New York: Clarendon Press; Oxford University Press.

Bennett, Jonathan. (1978). "On Maximising Happiness." http://www.earlymoderntexts.com/ $\mathrm{jfb} /$ maxhap.pdf.

Berel Dov Lerner. (2010). "Could I Have Been a Woman?: Meditations on a Controversial Benediction." Philosophy and Literature 34 (2): 425-34. https://doi.org/10.1353/ phl.2010.0010.

Blackorby, Charles, Walter Bossert, and David Donaldson. (2005). Population Issues in Social Choice Theory, Welfare Economics, and Ethics. Cambridge University Press.

Boonin, David. (2014). The Non-Identity Problem and the Ethics of Future People. New York, NY: Oxford University Press.

Bradley, Ben. (2008). "The Worst Time to Die." Ethics 118 (2): 291-314.

Bradley, Ben, and Kris McDaniel. (2013). "Death and Desires." In The Metaphysics and Ethics of Death: New Essays, edited by James Stacey Taylor. http://citeseerx. ist.psu.edu/viewdoc/download?doi=10.1.1.404.8057\&rep=rep1\&type=pdf.

Broad, C. D. (1933). "Is "Goodness" a Name of a Simple Non-Natural Quality?" Proceedings of the Aristotelian Society, New Series, 34 (January): 249-68.

Broome, John. (1993). "Goodness Is Reducible to Betterness: The Evil of Death Is the Value of Life." In The Good and the Economical: Ethical Choices in Economics and Management, edited by Peter Koslowski and Yuichi Shionoya, 70-84. Springer Verlag.

(1999). Ethics Out of Economics. Cambridge; New York: Cambridge University Press. (2004). Weighing Lives. Oxford; New York: Oxford University Press.

Bykvist, Krister. (2007). "The Benefits of Coming into Existence." Philosophical Studies 135 (3): 335-62. https://doi.org/10.1007/s11098-005-3982-x.

Chang, Ruth. (2002). "The Possibility of Parity." Ethics 112 (4): 659-88. https://doi.org/ $10.1086 / 339673$.

Dasgupta, Partha. (1988). "Lives and Well-Being." In Distributive Justice and Inequality, edited by Prof Dr Wulf Gaertner and Prof Dr Prasanta K. Pattanaik, 15-38. Springer Berlin Heidelberg. http://link.springer.com/chapter/10.1007/978-3-642-73816-6_2.

(1994). "Savings and Fertility: Ethical Issues." Philosophy \& Public Affairs 23 (2): 99-127. https://doi.org/10.1111/j.1088-4963.1994.tb00007.x.

Dorr, Cian. (2016). “To Be F Is to Be G.” Philosophical Perspectives 30 (1): 39-134.

Edgington, Dorothy. (2014). "Indicative Conditionals." In The Stanford Encyclopedia of Philosophy, edited by Edward N. Zalta, Winter 2014. Metaphysics Research Lab, Stanford University. https://plato.stanford.edu/archives/win2014/entries/conditionals/.

Ewing, A. C. (1939). "A Suggested Non-Naturalistic Analysis of Good.” Mind, New Series, 48 (189): $1-22$.

Fehige, Christoph. (1998). “A Pareto Principle for Possible People.” In Preferences, edited by Christoph Fehige and Ulla Wessels, 509-43. De Gruyter.

Fleurbaey, Marc, and Alex Voorhoeve. (2015). "On the Social and Personal Value of Existence." In Weighing and Reasoning: Themes from the Philosophy of John Broome, edited by Iwao Hirose and Andrew Reisner. Oxford University Press.

Frick, Johann. (2014). "'Making People Happy, Not Making Happy People': A Defense of the Asymmetry Intuition in Population Ethics." Ph.D. Dissertation, Harvard University. http://dash.harvard.edu/handle/1/13064981.

Fritz, Peter, and Jeremy Goodman. (2017). "Counting Incompossibles.” Mind 126 (504): 10631108. https://doi.org/10.1093/mind/fzw026. 
Goodman, Jeremy. (2016). "An Argument for Necessitism*." Philosophical Perspectives 30 (1): 160-82. https://doi.org/10.1111/phpe.12086.

Handfield, Toby. (2011). "Absent Desires." Utilitas 23 (04): 402-27. https://doi.org/ $10.1017 /$ S0953820811000306.

Harman, Elizabeth. (2004). "Can We Harm and Benefit in Creating?" Philosophical Perspectives 18 (1): 89-113. http://onlinelibrary.wiley.com/doi/10.1111/j. 1520-8583.2004.00022.x/full.

Heathwood, Chris. (2017). "Which Desires Are Relevant to Well-Being?" Noûs. https://doi.org /10.1111/nous. 12232 .

Heyd, David. (1988). "Procreation and Value Can Ethics Deal with Futurity Problems?" Philosophia 18 (2): 151-70. http://www.springerlink.com/index/1222K81 4631X546U.pdf.

Holtug, Nils. (2001). "On the Value of Coming into Existence." The Journal of Ethics 5 (4): $361-84$.

Hurka, Thomas. (1993). Perfectionism. New York: Oxford University Press.

Lin, Eden. (2017). "Welfare Invariabilism." Ethics 128 (2): 320-45. https://doi.org/ $10.1086 / 694272$.

McDaniel, K., and B. Bradley. (2008). "Desires.” Mind 117 (466): 267-302. https://doi.org/ $10.1093 / \mathrm{mind} /$ fzn044.

McMahan, Jeff. (1998). "Preferences, Death, and the Ethics of Killing." Fehige and Wessels, 471-502.

(2002). The Ethics of Killing: Problems at the Margins of Life. Oxford Ethics Series. New York: Oxford University Press.

. (2013). "Causing People to Exist and Saving People's Lives." The Journal of Ethics 17 (1-2): 5-35. https://doi.org/10.1007/s10892-012-9139-1.

(2015). "The Comparative Badness for Animals of Suffering and Death.” In The Ethics of Killing Animals, edited by Tatjana Viŝak and Robert Garner. Oxford University Press. https://www.oxfordscholarship.com/view/10.1093/acprof:oso/9780199396078.001. 0001/acprof-9780199396078-chapter-5.

(2019). "Early Death and Later Suffering." In Saving People from the Harm of Death, edited by Espen Gamlund and Carl Tollef Solberg. Oxford University Press. https://www.oxfordscholarship.com/view/10.1093/oso/9780190921415.001.0001/ oso-9780190921415-chapter-9.

Narveson, Jan. (1967). "Utilitarianism and New Generations." Mind 76 (301): 62-72. http://mind.oxfordjournals.org/content/LXXVI/301/62.full.pdf.

Nebel, Jacob M. (2018). "The Good, the Bad, and the Transitivity of Better Than*." Nous 52 (4): 874-99. https://doi.org/10.1111/nous. 12198.

(2019). "An Intrapersonal Addition Paradox." Ethics 129 (2): 309-43. https://doi.org/10.1086/700085.

Parfit, Derek. (1984). Reasons and Persons. Oxford: Clarendon Press.

(2011). On What Matters. V. 1. Oxford: Oxford University Press.

(2017). "Future People, the Non-Identity Problem, and Person-Affecting Principles." Philosophy \& Public Affairs 45 (2): 118-57. https://doi.org/10.1111/papa.12088.

Pummer, Theron. (2019). "The Worseness of Nonexistence." In Saving People from the Harm of Death, edited by Espen Gamlund and Carl Tollef Solberg, 215-28. New York: Oxford University Press.

Rabinowicz, Wlodek. (2008). "Value Relations." Theoria 74 (1): 18-49. https://doi. org/10.1111/j.1755-2567.2008.00008.x.

(2009). "Broome and the Intuition of Neutrality." Philosophical Issues 19 (1): 389-411. http://onlinelibrary.wiley.com/doi/10.1111/j.1533-6077.2009.00174.x/full.

(2012). "Value Relations Revisited." Economics and Philosophy 28 (02): 133-64. https://doi.org/10.1017/S0266267112000144. 
Rachels, Stuart. (1998). "Counterexamples to the Transitivity of Better Than." Australasian Journal of Philosophy 76 (1): 71-83. https://doi.org/10.1080/00048409812348201.

Roberts, Melinda A. (2003). "Can It Ever Be Better Never to Have Existed at All? Person-Based Consequentialism and a New Repugnant Conclusion." Journal of Applied Philosophy 20 (2): 159-85.

Scanlon, Thomas. (1998). What We Owe to Each Other. Cambridge, Mass.: Belknap Press of Harvard University Press.

Scheffler, Samuel. (2013). Death and the Afterlife. Edited by Niko Kolodny. Oxford University Press.

Shiffrin, Seana Valentine. (1999). "Wrongful Life, Procreative Responsibility, and the Significance of Harm." Legal Theory 5 (2): 117-48.

Singer, Peter. (2011). Practical Ethics. 3rd ed. New York: Cambridge University Press.

Temkin, Larry S. (1987). "Intransitivity and the Mere Addition Paradox." Philosophy \& Public Affairs 16 (2): 138-87. . (1996). "A Continuum Argument for Intransitivity." Philosophy \& Public Affairs 25 (3): $175-210$.

Thomas, Teruji. (2016). "Topics in Population Ethics.” D.Phil. Thesis, University of Oxford.

Williams, Bernard. (1999). Problems of the Self: Philosophical Papers 1956-1972. Reprint. Cambridge: Cambridge Univ. Press.

Williamson, Timothy. (2013). Modal Logic as Metaphysics. Oxford University Press. 